\title{
Anthelmintic Activity of Curcuma Aeruginosa Roxb Extract on Fasciola gigantica in Vitro
}

\author{
Henni Vanda ${ }^{1}$, Rizki Parindra ${ }^{2}$, Muhammad Hambal $^{3 *}$, and Farida Athaillah ${ }^{3}$ \\ ${ }^{1}$ Laboratory of Pharmacology, Faculty of Veterinary Medicine, Universitas Syiah Kuala \\ ${ }^{2}$ Study Program of Veterinary Education, Faculty of Veterinary Medicine, Universitas Syiah Kuala \\ ${ }^{3}$ Laboratory of Parasitology, Faculty of Veterinary Medicine, Universitas Syiah Kuala
}

\begin{abstract}
Fasciola gigantica is a parasite that causes a disruption of the metabolism of fats, proteins, and carbohydrates, which interferes growth and causes death. Curcuma aeruginosa Roxb extract is one of the medicinal plants which has been used to treat several diseases. The aim of this study was to determine the effect of methanolic extract of $C$. aeruginosa Roxb on $F$. gigantica, including mortality time and histopathological changes that occurred after treatment. This study used a completely randomized design with five replications. The flukes were soaked in three different extract concentrations: $10 \%$ (T1), 25\% (T2), and $50 \%$ (T3) (w/v). Phosphate buffered saline (PBS) solution was used as a negative control (C1) and albendazole as the positive control (C2). The mortality time of $F$. gigantica in each group was calculated, and the dead flukes were prepared for histopathological study. The data were analyzed by Analysis of variance. The results showed that $C$. aeruginosa extracts at the concentration of 10,25 and $50 \%$ caused the death of the flukes within 75, 57 and 48 minutes, respectively., Histopathological observations showed that the extract caused breakage of tegument which is an important organ in the respiratory process and nutrient absorption. This study concluded that $C$. aeruginosa extract exhibited anthelmintic activity towards $F$. gigantica in vitro.
\end{abstract}

Keywords: Fasciola gigantica, Curcuma aeruginosa Roxb extract, albendazole, pathological changes.

\section{Introduction}

Fasciolosis is a disease that causes low productivity and a low population of ruminants, which contribute to great economic loss. Fasciolosis is caused by trematode Fasciola gigantica (tropic) and Fasciola hepatica (subtropic) which occurred in the liver and bile duct. Animals which are exposed to fasciolosis are usually ruminants, but several cases were also reported in human. The control of fasciolosis mainly by anthelmintic drugs, however, the effectiveness of the drugs is decreased due to indiscriminate use which leads to parasite resistance. Furthermore, chemical drugs may be toxic to animals, and there is also a chemical residue problem that needs to be resolved [1]. The search for safe, effective, and affordable anthelmintic is compulsory, and plant-based anthelmintic is a preference to cope with these problems [2].

One of the plants which have been used as medicine is Curcuma aeruginosa Roxb. This plant is also known as black turmeric, belongs to the family of Zingiberaceae, which has been used as raw material for medicine and cosmetics in Southeast Asia. The rhizome of $C$. aeruginosa was traditionally used to treat gastrointestinal problems such as diarrhea and fungal infections [3]. The rhizome was also reported to have pharmacological activities in treating various diseases such as tumors, asthma, and bronchitis [4]. However not much information is available about the use of this plant as anthelmintic, therefore this study was conducted to explore the ability of $C$. aeruginosa extract as anthelmintic to treat fasciolosis in vitro.

\section{Materials and Methods}

\subsection{Collection of the Parasites}

Mature $F$. gigantica were collected from liver cattle slaughtered at Banda Aceh abattoir in PBS solution and examined immediately to avoid any disruption.

\subsection{Plants Extraction}

Five hundred grams of the dried ground rhizome of $C$. aeruginosa Robx. were extracted with cold maceration using $96 \%$ methanol. The plants were soaked in $2 \mathrm{~L}$ of methanol for three days at room temperature. The filtrate was then collected and the solvent was removed by rotary evaporator at $40{ }^{\circ} \mathrm{C}$. The crude extract was resuspended in phosphate-buffered saline (PBS) and diluted to the desired concentration. If necessary, $0.5 \%$ of carboxymethyl cellulose (CMC) was added to the solution.

\subsection{Anthelmintic assay on Fasciola gigantica}

This study used three different concentrations for each extract $(\mathrm{n}=5)$ : T1 $(10 \%), \mathrm{T} 2(25 \%)$, and T3 $(50 \%)$. Albendazole $0.24 \mathrm{mg} / \mathrm{ml}$ was used as the positive control

* Corresponding author: hambal.m@unsyiah.ac.id 
(C2), and PBS was used as the negative control (C1). The flukes were placed in petri dishes for each treatment and incubated at room temperature. The observation was conducted every 15 minutes until all the flukes died. The fluke's motility was recorded by the score index, and the mortality time was recorded.

\subsection{Mortality time}

Mortality time was determined by observing the motility of the flukes and examined under the microscope. The movement of the flukes was observed until they showed no movement. To ensure the flukes had died, they were submerged into lukewarm water $\left(60^{\circ} \mathrm{C}\right)$.

\subsection{Sample Preparation for Histopathology Examination}

The flukes were further examined for histopathological changes after $C$. aeruginosa extract treatment. The flukes were set for paraffin embedding and fixed in $10 \%$ formalin for 24 hours, then dehydrated in ascending concentration of ethanol. The samples were cleared by xylol and then embedded in paraffin wax. The samples were dissected longitudinally at 3-5 $\mu \mathrm{m}$ thickness and stained with hematoxylin and eosin. The observation of abnormalities was carried out on each section under a light microscope (Olympus, Tokyo, Japan), and photographed [1].

\section{Results and Discussion}

The mortality time of flukes in each treatment was varied, and the longest duration was owned by negative control with the average time was 411 minutes. The average mortality time for $\mathrm{T} 1, \mathrm{~T} 2$, and $\mathrm{T} 3$ were 75,57 , and 48 minutes, respectively. As for positive control, all of the flukes were dead within 30 minutes. The mortality time of flukes is provided in Figure 1.

Phosphate buffered saline was used as a negative control as this solvent has osmolarity and ions concentration similar to body fluid (isotonic). PBS is also non-toxic therefore it is suitable for biological research. From Figure 1 it was shown that the flukes were stable in PBS until 180 minutes, then the motility was decreased gradually till 345 minutes. At 355 minutes, all flukes had no motility, and at 495 minutes all flukes were dead.

The treatment group had interesting results, where T3 (50\% extract) showed the best activity on $F$. gigantica with average mortality time was 48 minutes. At 45 minutes of treatment, $60 \%$ of flukes were dead, and at 60 minutes, all flukes died. For T2 (25\% extract), all flukes showed no body movement at 30 minutes, and they were all dead at 75 minutes. T1 (10\%) had the lowest activity, flukes showed no movement at 45 minutes, then $80 \%$ of flukes died at 75 minutes. Within 90 minutes, all flukes died.

The mortality time of T1 was significantly different from $\mathrm{C} 1(\mathrm{p}<0.05)$, whereas $\mathrm{T} 2$ and $\mathrm{T} 3$ had no different from $\mathrm{C} 1$ ( $\mathrm{p}>0.05)$. The concentration of $25 \%$ and $50 \%$ had the same effect as albendazole on $F$. gigantica in vitro, therefore this extract had potential as anthelmintics (Table
1). This finding is essential since not much information is available for the use of this extract to treat trematodes.

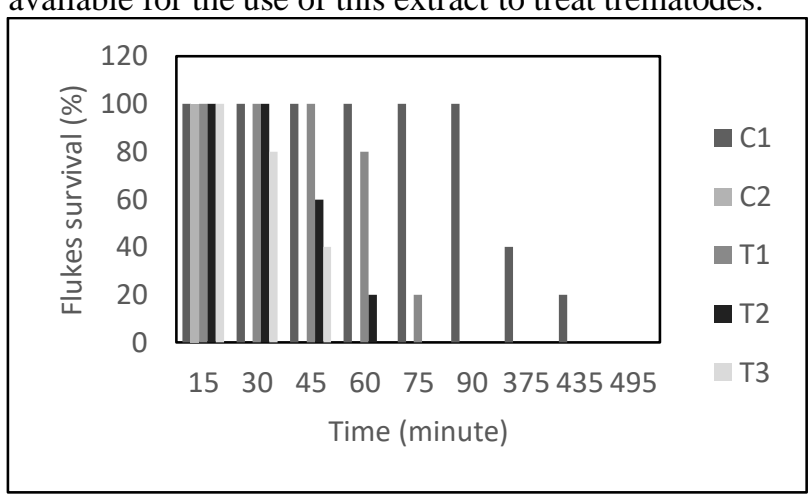

Figure 1. Percentage of Fasciola gigantica survived after treatment. C1: negative control; $\mathrm{C} 2$ : positive control; $\mathrm{T} 1: 10 \%$ extract; T2: $25 \%$ extract; $\mathrm{T} 3: 50 \%$ extract.

Table 1. Mortality time of $F$. gigantica in treatment and control group

\begin{tabular}{|c|c|c|c|c|c|}
\hline & \multicolumn{5}{|c|}{ Mortality time } \\
\hline & $\mathrm{C} 1$ & $\mathrm{C} 2$ & $T 1$ & $T 2$ & $T 3$ \\
\hline $\begin{array}{l}\text { Fasciola } \\
\text { gigantica }\end{array}$ & $411 \pm 5.7^{\mathrm{c}}$ & $30 \pm 0.0^{\mathrm{a}}$ & $75 \pm 10.6^{\mathrm{b}}$ & $57 \pm 12.5^{\mathrm{ab}}$ & $48 \pm 12.5^{\mathrm{ab}}$ \\
\hline
\end{tabular}

Curcuma aeruginosa has been used as anthelmintic as reported by Siahaan et al. [5], they found out the decreased of worm infection in children after being treated by this rhizome. C. aeruginosa was also effective in treating adult worm and eggs of Ascaris suum in vitro [6]. However, little information is reported about using this plant for trematode infection.

Chemical composition of $C$. aeruginosa has been reported by several authors [7-11] which contained terpenes (curcumenol, isocurcumenol, germacrone), curcumin, demethoxycurcumin, steroids, phenols, tannins, and saponins. Monoterpenes and sesquiterpenes are acetylcholine antagonists, which interfere with muscle contraction of flukes, lead to paralysis, and eventually death.

Histopathological findings of the treatment group as well as positive control indicated the breakage of flukes' tegument, as shown in Figure 2. Tegument is an important organ for $F$. gigantica especially in respiration, nutrient absorption, and other metabolic function. Hamilton et al. [12] further stated that tegument has a role in suppressing host immune system, and driving inflammatory response associated with immunopathology. It explains the dead of flukes once the tegument is damaged. The spine of tegument also degenerated, and to some extent, perished.

Reproductive organs were also disrupted by this extract, indicated by the disintegration of testes (Figure 3). In the intestine of flukes, villi desquamation was also observed (Figure 4). 

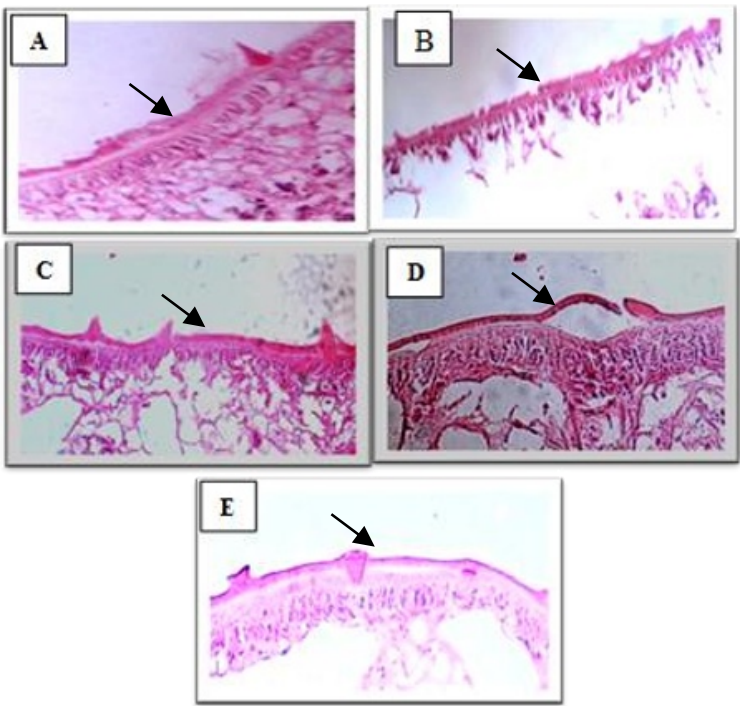

Figure 2. Histology of tegument of Faciola gigantica in control and treatment groups. A. C1 (negative control). B. C2 (positive control). C. $10 \%$ extract. D. $25 \%$ extract. E. $50 \%$ extract.
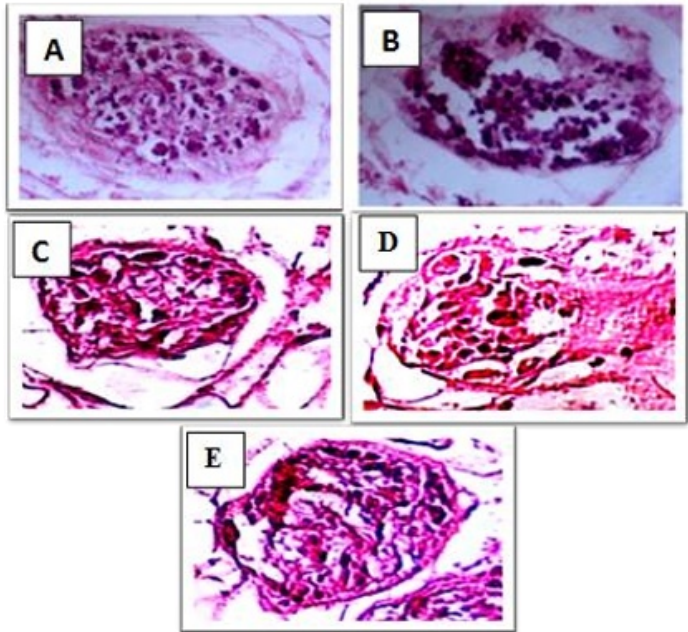

Figure 3. Histology of disintegrated testes of Fasciola gigantica in control and treatment groups. A. C1 (negative control). B. C2 (positive control). C. $10 \%$ extract. D. $25 \%$ extract. E. $50 \%$ extract.
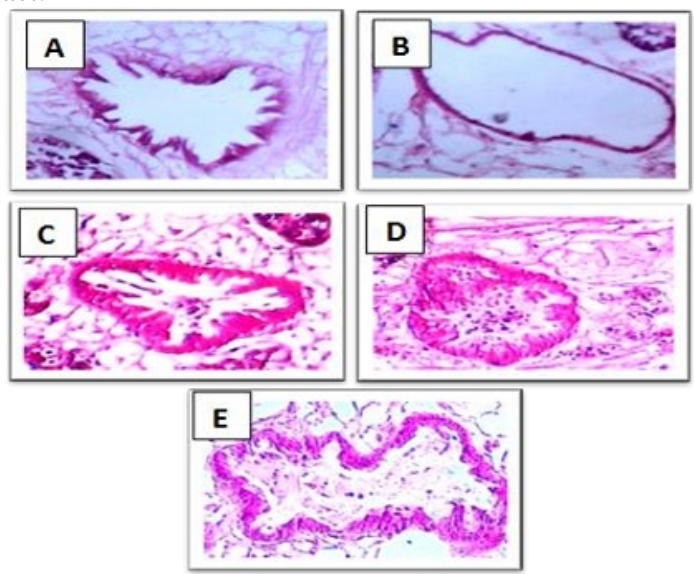

Figure 4. Histology of intestine desquamation of Fasciola gigantica in control and treatment groups. A. C1 (negative control). B. C2 (positive control). C. $10 \%$ extract. D. $25 \%$ extract. E. $50 \%$ extract.

\section{Conclusion}

This study showed that the $C$. aeruginosa extract had potential as an anthelmintic to treat fasciolosis caused by $F$. gigantica in vitro. The extract had an impact on tegument breakage which was an essential organ for $F$. gigantica in respiratory and nutrient absorption. The extract also disrupted reproductive organs, showed by the disintegration of testes, and it attacked intestine by causing intestine desquamation.

\section{References}

1. Jeyathilakan $\mathrm{N}$, Murali $\mathrm{K}$, Anandaraj $\mathrm{A}$, et al : Anthelmintic activity of essential oils of Cymbopogan nardus and Azadirachta indica on Fasciola gigantica. Journal of Veteterinary. Animal Science. 2010; 6(6):204209.

2. Khan MK, Sajid MS, Riaz H, et al : The global burden of fasciolosis in domestic animals with an outlook on the contribution of new approaches for diagnosis and control. Parasitology Research. 2013; 112(7):2421-2430.

3. Suphrom N, Pumthong G, Khorana N, et al: Antiandrogenic effect of sesquiterpenes isolated from the rhizomes of Curcuma aeruginosa Roxb. Fitoterapia. 2012;83(5):864-871.

4. Choudhury D, Ghosal M, et al : Development of single node cutting propagation techniques and evaluation of antioxidant activities of Curcuma aeruginosa Roxburgh rhizome.International Journal of Pharmacy and Pharmaceutical Science.2013;5(2):227-234.

5. Siahaan SAS, Handayani RS, Aryastami NK : Improving the use of Curcuma aeruginosa Roxb. as anthelmintic for children in Bogor Regency. Health Science Journal of Indonesia. 2017;8(2):95-101.

6. Utami WS, Hermansyah B : Anthelmintic Activity of Temu Ireng (Curcuma aeruginosa) on Adult Worm and Eggs of Ascaris suum in Vitro. Proceedings of the 40th Meeting of National Working Group on Indonesian Medicinal Plant, Bogor, Indonesia. 2011:161-162.

7. Sukari AH, Saad SM, Lajis NH, et al: Chemical Constituents and Bioactivity of Curcuma aeruginosa Roxb. Natural Product Sciences. 2007;13(3):175-179.

8. Kitamura C, Nagoe T, Prana MS, Agusta A, et al: Comparison of Curcuma sp. in Yakushima with $\mathrm{C}$. aeruginosa and $C$. zedoaria in Java by trnK gene sequence, RAPD pattern and essential oil component. Journal of Natural Medicines. 2007; 61(3):239-243.

9. Jose S, Thomas TD: Comparative phytochemical and anti-bacterial studies of two indigenous medicinal plants Curcuma caesia Roxb. and Curcuma aeruginosa Roxb. International Journal of Green Pharmacy. $2014 ; 8(1): 65-71$.

10. Simoh $\mathrm{S}$, Zainal A: Chemical profiling of Curcuma aeruginosa Roxb. rhizome using different techniques of solvent extraction. Asian Pacific Journal of Tropical Biomedicine. 2015;5(5):412-417.

11. Akarchariya N, Sirilun S, Julsrigival J, et al . : Chemical profiling and antimicrobial activity of essential oil from Curcuma aeruginosa Roxb., Curcuma glans K. Larsen \& J. Mood and Curcuma xanthorrhiza Roxb. Collected in Thailand. Asian Pacific Journal of Tropical Biomedicine. 2017;7(10):881-885.

12. Hamilton CM, Dowling DJ, Loscher CE, et al : The Fasciola hepatica tegumental antigen suppresses dendritic cell maturation and function. Infection and Immunity. 2009;77(6):2488-2498. 